\title{
A HISTÓRIA NAUFRAGADA DA NAU CONCEIÇÃO
}

\section{THE WRECKED HISTORY OF NAU CONCEIÇÃO}

João Leopoldo e Silva ${ }^{1}$

Resumo: Este artigo visa analisar a partir da leitura de um relato de naufrágio, compilado por Bernardo Gomes de Brito em seu livro História Trágico-Marítima, de 1735, a relação entre o conhecimento científico e o progresso com a experiência portuguesa da época dos descobrimentos, das navegações. O relato a ser analisado é o naufrágio da nau Conceição, em 1555.

Palavras-chave: Século XVI, Nau, Naufrágio, Império português.

Abstract: This article aims to analyze from the reading about a shipwreck, compiled by Bernardo Gomes de Brito in his book História Trágico-Marítima, 1735, the relation between scientific knowledge and progress with the Portuguese experience in the Age of Discovery, where the sailings were priority of the Portuguese Empire. The report to be analyzed is the sinking of the nau Conceição, in 1555.

Keywords: Sixteenth century, Nau, Shipwreck, Portuguese Empire.

A Era dos Descobrimentos é o nome dado ao período datado entre os séculos XV e XVI, na qual a Península Ibérica, após um longo e efervescente período de desenvolvimento científico, marcado principalmente pela presença moura e judia na região, lançou-se no mar aberto, no desconhecido, em busca de novos mercados, novas terras e novos

\footnotetext{
${ }^{11}$ Aluno do $5^{\circ}$ semestre de História na PUC-SP, orientado pelo Prof. Dr. Amilcar Torrão Filho. Lattes: http://lattes.cnpq.br/8429440645087139.
} 
mundos. Alcançaram não somente territórios e portos, mas principalmente o auge de seu poderio militar e de sua troca de influências.

Porém tal empreitada, moldada por sacríficos e desastres, produziu muitos mártires, muitas perdas que não podemos deixar no fundo do mar. Uma citação marcante de Francisco Ferreira de Lima em seu texto Os padecimentos do Império: Gabriel Soares de Sousa e sua pequena Trágico-Marítima nos ajuda a compreender a ideia:

\begin{abstract}
“A bem dizer, tal ceifa em vidas, seja qual for o número, deve ser entendida como uma necessidade vital, talvez seja melhor dizer uma necessidade mortal, do Império. Trata-se de uma, assim se deve dizer, morte ritualística, verdadeiro exercício de canibalismo, através do qual o Império chora" (Lima, 2006: 181).
\end{abstract}

Paolo Rossi trata a questão dos descobrimentos logo no início de seu livro Naufrágios sem espectador: A idéia de progresso: "a viagem não oferece certezas, mas apenas esperanças" (Rossi, 2000: 23). O ato de sair da terra firme e ir em direção ao desconhecido só é possível após uma longa era de estudos (leia-se progressos) que culminou na criação e aperfeiçoamento da chamada ciência náutica portuguesa. Porém há uma certa contradição ou, melhor dizendo, um lapso, que a razão, mãe da ciência, não consegue tapar: o naufrágio.

A construção das caravelas e naus pelos portugueses do século XVI tinham como objetivo, assim como as baluartes nas fortalezas, "resistir a grandes pressões físicas contrárias" (Doré, 2010: 215) e ataques militares de outras nações. Mas temos muitos casos relatados em que tal façanha da engenharia naval foi engolida pelo mar. Primeira- 
mente é importante entender como a nau era vista e planejada para entender sua presença e importância no contexto das expansões marítimas, principalmente na costa indiana, onde o Império Português exerceu grande influência e domínio não só em relação às populações locais e seu comércio, mas de monopólio e enfrentamento com outras nações expansiosistas como os turcos, os persas, os holandeses e ingleses. $\mathrm{O}$ domínio sobre o comércio dos mares traria a Portugal não somente riquezas para seus cofres mas como também importantes títulos.

Andréa Doré, em seu livro Sitiados - Os cercos às fortalezas portuguesas na Índia (1498 - 1622), pode nos ajudar a entender como era constituído o poderio militar das caravelas a partir da comparação com as fortalezas portuguesas na Índia. Doré defende que a função das fortalezas portuguesas na Ásia era de "desempenhar, a um só tempo, a função de refúgio, de dominação e de controle” (Doré, 2010: 211). Assim como as fortalezas, navios eram projetados e construídos para serem altamente fortificados a fim de enfrentar possíveis confrontos humanos e também resistir “a fúria dos elementos da natureza” (Doré, 2010: 212), mas sem nunca esquecer suas funções primordiais: comércio e guerra.

Doré avança na ideia e procura reconstruir um pouco da história náutica militar, dizendo que "durante o século XV, os navios funcionavam como “castelos navais móveis" (Doré, 2010: 214) e que

“o infante D. Henrique [1394 - 1460, um dos mais importantes infantes da época das Descobertas] teria sido o primeiro a incluir peças de artilharia a bordo das caravelas, mas sem resultado. D. João II, em seguida, construiu peças de bronze para equipar os navios, resolvendo o problema do desequilíbrio instalando-as 
numa coberta situada em um plano inferior ao convés e no corpo dos navios" (Doré, 2010: 214).

Simbolicamente, podemos relacionar os dois, fortaleza e navio, como o navio sendo uma fortaleza flutuante e as fortalezas, como navios ancorados em pedra (Doré, 2010: 215). O poderio militar e o objetivo nos quais ambos eram construídos se mesclam e caminham juntos: a fortaleza dando apoio aos navios para se reabastecerem e seguirem viagem, enquanto os navios apoiam seus porto-seguros em tempos de guerra.

Tanto a fortaleza em terra firme como o navio em alto-mar representavam o Império Português em sua integridade simbólica, um pedaço do Império em alto mar e outro em terra firme, no território, que era militarmente ou comercialmente conquistado. Muitas concessões foram feitas a portugueses por povos e nações indianas (poderes locais) em troca de paz ou aliança.

Não podemos deixar de lado a forma como ambos os espaços se organizavam internamente: não existiam grupos sociais homogêneos na fortaleza, seu contingente populacional não era formado apenas por soldados ou por homens de carreira militar, mas por diversas profissões que tinham funções específicas, e que se complementavam e davam suporte aos que a defendiam. Já no navio, sua organização interna também respeitava uma rígida ordem hierárquica, que afetava a função de cada homem dentro na nave, assim como lugar aonde cada um iria dormir. Desta maneira, Doré chega a conclusão que o domínio português na Índia, tanto em forma de navio como de fortaleza, pode ser entendido 
como uma dominação cercada, ou seja, na fortaleza temos a ação direta da Coroa Portuguesa dentro dos muros, através de uma forte hierarquia composta de regras e objetivos, e, dos muros para fora, a constante ameaça de cercos. Imagem semelhante encontramos nos navios, que, apesar de sua organização ser parecida, combatem nações rivais, calmarias e naufrágios.

O florescimento renascentista português é o motivo principal do alto desenvolvimento técnico e científico que proporcionou o destaque marítimo luso. Segundo Joaquim Barradas de Carvalho em sua obra $O$ Renascimento Português (em busca da sua especificidade), a primeira ideia a ser desenvolvida é que o conceito de renascimento é muito mais amplo que o conceito de humanismo, no qual o segundo "não cobre senão uma pequena parte, algumas vezes mesmo muito pequena do conceito de renascimento" (Carvalho, 1980: 9) e que este é especificamente o caso de Portugal. O autor cita uma frase de Luís de Matos onde comenta e relaciona o conceito de Renascimento português com seu desenvolvimento: "O aparecimento, por um lado, de uma abundante literatura ultramarina, o aperfeiçoamento da ciência náutica, por outro lado, e, enfim, a experiência vivida dos Portugueses, como todas suas consequências, representam, sem dúvida, a contribuição mais válida do Renascimento português".

Desta citação devemos focar principalmente na palavra e no conceito de consequências. Mas, diante dela, devemos analisar suas causas. Joaquim Barradas de Carvalho afirma que os Descobrimentos são o grande ganho do Renascimento português, ambos se completam e for- 
mam uma "placa giratória" da história de Portugal:

"O Portugal de antes, da Idade Média, era já uma preparação para o seu Renascimento, o Renascimento português. O Portugal de depois, da época moderna e contemporânea, é uma consequência dos descobrimentos marítimos, do seu Renascimento" (Carvalho, 1980: 13).

O imaginário expansionista, afirma Barradas de Carvalho, é muito bem desenvolvido na "literatura portuguesa de viagens dos séculos XV e XVI e a literatura científica e técnica a esta estreitamente associa$d a$ ". A literatura de viagens se desenvolve junto da época dos Descobrimentos, que se estende de 1453 a 1508, e notamos o surgimento de novos autores com temas até então não trabalhados:

"Homens novos, vivendo num outro clima social e mental, homens com outros interesses e tendo uma nova escala de valores para julgar as coisas e os acontecimentos. A sua origem, o seu meio social, o seu gênero de vida, são diferentes. E com o seu gênero de vida, a sua consciência" (Carvalho, 1980: 17).

Compondo um tipo de literatura que segue um caminho oposto da literatura épica, tendo como exemplo Os Lusíadas, podemos dizer que os relatos de naufrágios fazem parte do imaginário português no que se diz respeito principalmente ao medo e o fracasso. Seu uso está diretamente relacionado a divulgação da história que o desastre procede, no qual o autor, sendo ele anônimo (alguns relatos não possuem autoria) ou nomeado, têm a pretenção e o objetivo informar e alertar marinheiros até mesmo a própria família deles sobre possíveis perdas - sobre os 
perigos de se lançar em alto mar. A publicação dos relatos de naufrágio na História Trágico-Marítima compilados por Bernardo Gomes de Brito em 1735 (no século XVIII, período pós-auge do Império português) como gênero literário abre novas possibilidades de estudo a estes documentos, como a interdisciplinidade entre História e Literatura e outros pontos de vista sobre as viagens portuguesas, no qual o artigo está inserido.

Afirmando que o avanço pelo oceano Atlântico tem início em Portugal, proveniente do Renascimento português de Barradas de Carvalo, Patrícia Seed, no capítulo quatro de seu livro Cerimônias de posse na conquista europeia do novo mundo, desenvolve a ideia que Portugal foi a vanguarda exploradora, os primeiros homens a saírem do continente e irem ao encontro do desconhecido com o objetivo de descobrir e comercializar: "Foram os primeiros europeus a comerciar diretamente com os povos africanos das regiões abaixo do Saara e da atual Indonésia, os primeiros a ter contato com os povos do Brasil" (Seed, 1999, p.143).

Seed se baseia no desenvolvimento técnico e científico português para dar base à sua tese. Iniciando seu texto contextualizando Pedro Nunes, cosmógrafo real do rei Dom João III, e Mestre João, astrônomo e chefe dos pilotos da marinha portuguesa, no século XVI, ela procura estabelecer relação entre progresso, prática científica, descobrimento e posse:

"Nem os ingleses nem outras potências européias da época con- 
sideravam que a descoberta criava oficialmente o domínio. Mas os portugueses sim. Embora ocasionalmente plantassem objetos, como pilares de pedra, para indicar a extensão de suas descobertas, sua habilidade em estabelecer a latitude de um novo lugar fornecia a principal prova de sua realização" (Seed, 1999, p.145).

Seed afirma que diferentemente de outras nações, como Inglaterra e França, no qual o ato de pisar, construir e realizar uma missa legitimava a posse, para Portugal era a ciência quem dizia e comprovava que uma nova terra havia sido encontrada.

Mas por trás de tais descobertas e dos humanistas e pilotos portugueses, há a ciência náutica, desenvolvida por árabes e judeus, expulsos da Península no fim do século XV, e aperfeiçoada por cristãos-novos e portugueses. De fato foi Mestre João "o primeiro europeu a fazer a descrição exata da mais famosa constelação de todos os novos céus, o Cruzeiro do Sul” (Seed, 1999, p.147), mas a rigor, completa Seed, não era nova. Os árabes o haviam nomeado com base em formas geométricas o quadrilátero -, assim como os polinésios. Porém, seu estudo matemático e astronômico visando a navegação tem autoria portuguesa. $\mathrm{O}$ desenvolvimento de uma nova ténica não visava e não se limitava a somente descobrir, mas também viabilizar objetivos militares, econômicos e estratégicos.

Patrícia Seed deixa explícita a ativa participação da coroa portuguesa em financiar astrônomos, astrólogos, matemáticos e mestres em navegação no desenvolvimento do que passaria a ser parte do imaginário português. Mas não esquece do legado e das tradições que os mouros desenvolveram e, posteriormente, deixaram na Península com sua ex- 
pulsão.

Os temas que permeiam a literatura de viagem passam por diários de bordo que relatam o dia-a-dia das viagens como também aos mais importantes para nosso estudo: as crônicas, as descrições de terras, os livros de cosmografia, os regimentos de navegação, os guias técnicos náuticos e, finalmente, os relatos de naufrágios. Os relatos, diferentemente dos outros documentos, nos mostram o ponto em que o Império Português falha, aonde ele erra e naufraga. Sua razão não permeia as conquistas e as vitórias mas as derrotas, assim como seus desdobramentos: mostram um poderio marítimo forte e bem preparado mas que muitas vezes não consegue atingir seus objetivos.

\section{O Naufrágio da Nau Conceição}

A História Trágico-Marítima de Bernardo Gomes de Brito, fonte formada pela compilação de relatos de naufrágios ocorridos no século XVI, mais especificamente entre 1552 e 1596, é fruto do desenvolvimento renascentista português e de suas viagens. Existem diversas publicações deste livro e dos relatos, algumas já digitalizadas e disponíveis no sítio eletrônico da Biblioteca Nacional de Portugal, porém a escolha feita para este artigo é uma publicação de 1998 pela editora Contraponto do Rio de Janeiro. O motivo desta escolha esta relacionado a linguagem atualizada, com o português contemporâneo, que esta edição trás sem alterar muito seu conteúdo, possibilitando ao leitor do artigo a leitura sem esforço das passagens destacadas.

Partiremos agora para a analise do relato propriamente escolhido: 
Relação do naufrágio da nau Conceição que era capitão Francisco Nobre, a qual se perdeu nos baixos de Pêro dos Banhos aos 22 dias do mês de agosto de 1555. Escrita por Manuel Rangel, o qual se achou no dito naufrágio e foi depois ter a Cochim em janeiro de 1557.

Logo no seu título já sabemos que quem narra o desastre é um sobrevivente. Também nos é dito o lugar e a data do naufrágio: nos baixos de Pêro dos Banhos, um pequeno atol ${ }^{2}$ localizado no Oceano Índico e o dia exato da tragédia, no dia 22 de agosto de 1557, período de grandes investimentos em viagens para a Índia em busca de comércio e de fixação territorial.

O relato é composto por três grandes partes, apesar de não serem divididas pelo autor. A primeira inicia-se em abril de 1555, onde nos é apresentada a companhia, as naus e seus capitães, que eram cinco:

"Acabando todos nós de ouvir missa, deram todas as naus que iam para esta comprida viagem da Índia, à vela, as quais eram cinco, e de todas ia por capitão-mor D. Leonardo de Sousa na nau Galega, e em sua companhia as naus S. Pedro, Assunção, S. Filipe, e esta nossa mal- afortunada por nome de Conceição, em que ia por capitão Francisco Nobre, e por piloto Afonso Pires, todos moradores de Lisboa". (Brito, 1998 [1735]: 97).

Após esta breve apresentação entramos no relato da viagem propriamente dita, onde ao passarem por Palma, a nau de D. Leonardo se afasta da nau do narrador, a nau Conceição, e nunca mais é vista por toda a viagem. Acontecem algumas desventuras relacionadas a calmari-

\footnotetext{
${ }^{2}$ Pequena ilha rodeada por corais.
} 
as ao passar pela costa de S. Tomé, onde ficam quarenta e três dias sem movimento e "sempre nos achávamos em três graus" (Brito, 1998 [1735]: 97), destaque importante aos "três graus", que nos leva a uma evidência do uso de aparelhos matemáticos e astronômicos, principalmente do astrolábio, para a navegação em alto mar. Sobrevivendo à calmaria de S. Tomé, eles passam pelo rercém-nomeado cabo da Boa Esperança, onde o autor nos adianta o que ocorrerá: eles haveriam de se perder e "em seis graus da linha da Índia” (Brito, 1998 [1735]: 97) a nau Conceição acabaria suas viagens.

A calmaria é tão perigosa quanto o naufrágio. Ao mesmo tempo que o mar engole a nau em um naufrágio, a calmaria o deixa à deriva: a ausência de ventos causa, além do gasto não previsto de mantimentos, previamente contados para um determinado tempo de viagem, causa danos à tripulação (sociedade temporária) formada para a viagem. Como confiar em um capitão, em um astrônomo ou em um piloto que deixa a tripulação à deriva? Que os leva diretamente para o meio de uma tempestade? Esta sociedade é ameaçada tanto pela imobilidade quanto pelo excesso de movimento.

Todos estavam convictos que estariam chegando próximo ao seu destino sem muito esforço quando alguns comentam sobre a tonalidade da água, que estaria muito verde, um péssimo sinal: estariam perto de alguns baixos (no caso perto de corais, perto de um atol). Tanto Cristóvão Lopes, estrenqueiro ${ }^{3}$ e experiente na carreira da Índia, quanto Afonso Pires, denominado como "guardião, que carteava sempre o Sol"

\footnotetext{
${ }^{3}$ Aquele que cuida das cordoalhas (cordas de aço) do navio.
} 
(Brito, 1998 [1735]: 98) - muito provavelmente o astrônomo e matemático que operava o astrolábio - procuraram avisar o piloto do perigo, porém sem sucesso. Afonso Pires diz ao piloto: "Piloto, olhai o que fazeis, que esta noite me faço com uns baixos" (Brito, 1998 [1735]: 98), porém logo recebe a resposta: "Ide mandar os grumetes ao convés, que eu sei o que nisto faço" (Brito, 1998 [1735]: 98). Procuram avisar o capitão, Francisco Nobre, porém este está dormindo e não o quiseram acordar. Começam a notar alguns pássaros a rodear o navio, e à medida que andam, mais pássaros se juntam a eles. O guardião procura novamente avisar o piloto, que não lhe escuta, e o impacto acontece no dia 22 de agosto de 1555, quatro meses após a saída de Lisboa, relatado por Manuel Rangel:

“indo a nau Conceição com vento à popa e mar bonança com as velas todas dadas, ao quarto da madorna, dous relógios rendidos, deu uma muito grande pancada, que pareceu que de todo se espedaçava" (Brito, 1998 [1735]: 99).

Logo após o impacto a tripulação entra em total desespero aclamando por salvação à Nossa Senhora:

“chamaram por Nossa Senhora, com uma grita que não nos ouvíamos uns aos outros, chorando e pedindo misericórdia a Nosso Senhor de nossos pecados, com vozes tão altas que parecia que se fundia ao Céu, e todos tínhamos aquela pela derradeira hora de nossa vida" (Brito, 1998 [1735]: 99).

A nau bate mais algumas vezes nos corais ao seu redor, e a tripulação junto de Afonso Pires, o guardião, procura desesperadamente sal- 
vá-la, mas sem "remédio nenhum de salvação senão aquele que Nosso Senhor milagrosamente nos quisesse dar" (Brito, 1998 [1735]: 100). Diante do naufrágio a ciência e a técnica podem pouco, os homens depositam suas esperanças em suas crenças metafísicas, ato que contrapõe o espírito ciêntífico e métrico, agente potente e abridor de caminhos para a própria situação em que se encontram; nesta situação a religião e o milagre podem auxiliá-los. É neste momento de calamidade que buscam a salvação, a fé, gritando o mais alto que podem para aliviar os pecados. Ao mesmo tempo que a ciência e os estudos os dão à eles a oportunidade de saírem de suas casas e cidades para irem ao encontro de populações e territórios, anteriormente inatingíveis, dão margem ao seu encontro com situações extremas, não científicas, não controláveis, onde precisam se superar e se unir para atingir o objetivo eminente e comum: a sobrevivência.

Os sobreviventes procuram salvar os mantimentos da nau e vêem um pedaço de terra com "muitos pássaros brancos com as pontas das asas pretas, a que chamam alcatrazes; e tanto que vimos aquele pedaço de terra damos muitas graças a Nosso Senhor" (Brito, 1998 [1735]: 101), ficando o batel (barco reserva, "salva-vidas") "no mar com os cofres de El-Rei” (Brito, 1998 [1735]: 101). Situações como esta nos mostram que em momentos de desespero as ordens do Império, ou os iniciais objetivos de comércio, ficam em segundo plano: o importante agora é a sobrevivência.

O capitão Francisco Nobre, o piloto, alguns marinheiros, Afonso da Gama e seu sobrinho, e alguns sobreviventes do naufrágio procuram 
fugir do local no batel, o que gera uma grande intriga entre os que não foram escolhidos para os acompanharem. Vemos que este tipo de situação é importante para entender que a tripulação do navio não é composta por um grupo homogêneo de pessoas, mas por todos os tipos sociais: de fidalgos e estudiosos a degredados, cada um ocupando o seu posto de uma maneira hierárquica, com os nobres no topo.

Os que ficam no atol, incluindo o autor do relato, elegem D. Álvaro de Ataíde, sobrinho do conde da Castanheira para o cargo de capitão, porém o autor critíca esta escolha. Apesar de ser fidalgo e de bons amigos, "não era para o cargo que lhe demos, por não ser temido e ser juntamente macebo" (Brito, 1998 [1735]: 103). D. Álvaro estabelece uma série de regras de racionamento de mantimentos para poderem aguentar o maior tempo possível vivos, cada pessoa comendo "três castanhas, e tamanho queijo como duas unhas, e meio copinho de vinho, o qual levava três partes de água, e isso duas vezes, uma pela manhã e outra à noite" (Brito, 1998 [1735]: 104), sem contar os diversos pássaros que matam para complementar a alimentação. A eleição de um homem para os os governar e sua preocupação de racionar mantimentos demonstram a determinação e a necessidade de se manterem em civilidade e sociedade. Eles precisam, além de sobreviver fisicamente o naufrágio, procurar manter sua humanidade. $\mathrm{O}$ autor chega a citar que do momento em que chegam nos baixos de Pêro dos Banhos aos 25 dias de sua estadia, dos - estimados - dez mil pássaros só sobram dois mil. D. Álvaro procura limitar o uso da lenha para fogueiras e a matança de pássaros, porém, os homens não o obedecem (lembrando a própria crítica do au- 
tor). A água também é escassa, e são obrigados a cavar para encontrar mais e, quando a encontram, agradecem ao Nosso Senhor pelo milagre.

O momento que marca a transição do naufrágio para a sobrevivência é quando D. Álvaro decide construir um navio para procurar ajuda e retornar para os baixos a fim de salvar os que ficariam:

"D. Álvaro mandou apartar oito sacos de biscouto para levar e sessenta caixas de marmelada, das quais deixou obra de cinquenta, e levou trinta barris de quarta de conserva, e deixou alguns vinte e cinco. Levou duas dúzias de lançóis cosidos, e deixou oito para a gente que ficava na ilha; e assim deu um barril de farinha que saiu da nau; mandou fazer também empadas de pássaros, e cozeram-se em uma fornalhazinha que mandara fazer para o mar; e levou mais duas pipas e meia de vinho e deixou uma só, e assim três de água, sem deixar nem pouca nem muita; e uma caixa encourada cheia de prata lavrada e alguns capacetes e malhas e outras trouxas de fato, o qual levava também em barris, de que tudo carregou o navio, de maneira que por carregar fato deixou de levar gente que tinha dito, que diriam sessenta ou setenta pessoas, das quais não levou mais de quarenta" (Brito, 1998 [1735]: 106107).

A partir deste momento, para os cento e sessenta e seis que ficam, a esperança de sua salvação não está somente nas mãos de Nosso Senhor, mas nas mãos daqueles que estão saindo em busca de ajuda, nas mãos de D. Álvaro de Ataíde. Eles passam a se organizar melhor e criam um sentimento de irmandade até então não evidente no relato: “ao grande como o pequeno, e ao negro como ao branco, e desta maneira se governava e a gente toda como irmãos, sem entre eles haver nunca brigas, porque os que regiam não o consentiam, e quem havia mister castigo davam-lho" (Brito, 1998 [1735]: 109). 
A estadia na ilha passa a ser não apenas um inconveniente do destino mas uma etapa, o próprio purgatório a ser vencido: "Mas vivíamos com a esperança que tínhamos do socorro que nos podiam mandar da Índia [o sucesso de D. Álvaro], que com o que nos sustentávamos; e cada um procurava vigiar se vinha alguém que nos tirasse daquele purgatório" (Brito, 1998 [1735]: 110). Neste momento Manuel Rangel nos relata uma série de acontecimentos que vão minando esta estadia, mas garante que "não houve quem se quisesse amotinar a tomar o comer uns aos outros" (Brito, 1998 [1735]: 111), como se a integridade como seres humanos (não-bárbaros) portuguêses é mantida: ainda existe a formação de um pequeno "estado" - alguns eleitos para "governar" os mantimentos e centralizar as decisões - e a manutenção dos "bons costumes".

Cinco meses após o naufrágio, a "população de sobreviventes" se reduz drasticamente, principalmente pela fome e pela doença. $\mathrm{O}$ autor relata que "em janeiro faleceram trinta pessoas, e cada dia sepultávamos seis e sete pessoas, e não havia quem já tivesse forças para as poder enterrar, nem menos meter nas covas" (Brito, 1998 [1735]: 112). Manuel Rangel atribui a sobrevivência do grupo às custas de Nosso Senhor, que lhes mandava ervas, comida (animais como lobo ou tartaruga) e água. Fazem o uso da pesca a partir de anzóis feitos por alguns ferreiros sobreviventes, porém não é o suficiente e a insuficiência alimentar levam muitos a padecer.

Há um ponto que não esperam mais salvação: "Estando já (como disse) sem esperança de termos socorro nenhum da Índia, e que a maior parte da gente era falecida" (Brito, 1998 [1735]: 113) eles constroem um 
barco com o intuito de se salvarem, saírem do chamado "purgatório". No dia de São Pedro, 29 de junho, com a ajuda dos apóstolos, batizam o barco em honra ao Santo, patrono dos marinheiros. Todos os sobreviventes ajudam a construí-lo, não somente carpinteiros ou trabalhadores manuais mas também os fidalgos. Porém, o sucesso é atribuído a Deus: "Dizer a estas pessoas que fizeram o barco a ajuda e engenho que Deus lhes deu, era muito para pasmar, que de quantos o fizeram nenhum sabia tomar enxó nem machado na mão para o ordenar, senão Deus os metia em esforço e os ensinava" (Brito, 1998 [1735]: 114) - o que nos leva a questionar como aqueles que não tinham nenhuma experiência prática e rústica, já estando em minoria em relação o grupo inicial sobrevivente, aguentaram? Será que tiveram tratamento melhor aos que possuíam tal experiência mas padeceram?

Lançam-se ao mar "todos quantos éramos" (Brito, 1998 [1735]: 115) e passam trinta e três dias à deriva, passando fome e dificuldades. Não puderam levar uma grande quantidade de mantimentos pelo tamanho do barco e porque não os tinham em abundância. Econtram duas ilhas, e aportam em uma. Agradecem "em altas vozes dando Senhor graças, pois nos trazia à terra onde pudéssemos ser enterrados" (Brito, 1998 [1735]: 116). Neste momento se esbarram com um nativo, que os renova as esperanças mas ao mesmo tempo os deixa assustados, pois ele sai correndo e temem que possa voltar com um contigente para matálos. Novamente passam por diversas dificuldades relacionadas à alimentação e doença, até decidirem fazer um esquife e tentar a sorte na outra ilha, porém com apenas dez pessoas, deixando para trás algumas pesso- 
as (número que não é especificado) e três apóstolos. Chegam nesta outra ilha em agosto de 1556, todos doentes e fracos, mas conseguem recuperar suas forças comendo lagostas que encontram, atribuindo novamente este encontro à misericórdia de Deus.

Após se recuperarem, decidem retornar à primeira ilha "dos quais não achamos mais que dous quase mortos, e os padres apóstolos também mortos; quatro morreram à fome" (Brito, 1998 [1735]: 118), e isso lhes traz grande tristeza (principalmente a morte dos apóstolos). No dia cinco de novembro de 1556, inicia-se a fase final do relato: a salvação de Manuel Rangel, que avista duas velas na outra ilha. Dois homens saem em direção dos negros que vieram ao seu encontro, enquanto os outros pedem "a Deus misericórdia, que nos não deixasse morrer em mãos de negro, deitados por terra, chorando e pedindo perdão de nossos pecados" (Brito, 1998 [1735]: 118). Manuel Rangel lança-se ao mar e nada até o batel, onde é recebido, tendo a chance de dizer que são portugueses perdidos e que precisam de ajuda; perguntadm-lhe se tem dinheiro, ele responde que sim. O levam para a ilha e os portuguerses entregam sessenta cruzados, junto de beijos nas mãos e nos pés.

São conduzidos ao navio e levados para onde não tinham conhecimento, uma ilha onde havia um mouro como rei, onde são bem recebidos assim como nos outros dois reinos mouros que passaram antes de chegarem à Índia em janeiro de 1557. Interessante que não foram os portugueses que os salvaram, nem houve algum milagre, mas os próprios inimigos: os mouros.

Os relatos de naufrágio estão entre os documentos que a historio- 
grafia tradicional não trabalha. Abordando apenas o sucesso de grandes expedições, como por exemplo de Vasco da Gama ou de Cristóvão Colombo, os relatos delatam que nem todas as embarcações que saíam dos portos chegavam ao seu destino deixando, assim, de cumprir seus objetivos como observado no relato da nau Conceição. Tal empreitada foi feita de sacríficos e desastres, que da margem para o surgimento deste tipo de literatura, composta não somente por literários portugueses da época, mas pelos próprios sobreviventes. É importante comentar a própria questão da memória envolvida nos relatos, como eles são feitos em um ambiente do pós-trauma, muitas informações podem ter sido perdidas ou adicionadas pelo autor.

Indo ao encontro de um autor clássico, Luís de Camões, em seu livro épico Os Lusíadas, o autor procura descrever as conquistas do Império Português de maneira a exaltá-las, utilizando-se até de elementos sobrenaturais, porém não deixa de fazer referências a naufrágios. Temos no Canto V três estrofes - XLVI a XLVIII - que fazem referência ao naufrágio da nau São João, que aparece na História TrágicoMarítima, de Bernardo Gomes de Brito, em forma de relato.

\footnotetext{
"Outro também virá, de honrada fama/ Liberal, cavaleiro e namorado,/ E consigo trará a formosa dama/ Que Amor por grão mercê lhe terá dado./ Triste ventura e negro fado os chama/ Neste terreno meu, que, duro e irado,/ Os deixará dum cru naufrágio vivos,/ Para verem trabalhos excessivos.

Verão morrer com fome os filhos caros,/ Em tanto amor gerados e nascidos;/ Verão os cafres, ásperos e avaros;/ Tirar à linda dama seus vestidos;/ Os cristalinos membros e preclaros/ À calma, ao frio, ao ar, verão despidos,/ Depois de ter pisada, longamente,/
} 
Cos delicados pés a areia ardente.

E verão mais os olhos que escaparem/ De tanto mal, de tanta desventura,/ Os dous amantes míseros ficarem/ $\mathrm{Na}$ ferida e implacável espessura./ Alí, depois que as pedras abrandarem/ Com lágrimas de dor, de mágoa pura,/ Abraçados, as almas soltarão/ Da formosa e misérrima prisão.” (Camões, 1962 [1556]: 146-147).

Camões também faz referência ao Cabo das Tormentas no Canto V, estrofe XLIII:

\begin{abstract}
"Sabe que quantas naus esta viagem/ Que tu fazes, fizeram, de atrevidas,/ Inimiga terão esta paragem,/ Com ventos e tormentas desmedidas!/ E da primeira armada, que passagem/ Fizer por estas ondas insofridas,/ Eu farei de improviso tal castigo,/ Que seja mor o dano que o perigo!" (Camões, 1962 [1556]: 146).
\end{abstract}

De acordo com uma outra publicação de Os Lusíadas, de 1973, e comentada por Evanildo Bechara e Segismundo Spina, o verso "E da primeira armada, que passagem" faz "alusão ao temporal inesperado (d'improviso) que desabou sobre a armada comandada por Pedro Álvares Cabral, com destino à Índia, em 1500 e que fez naufragar quatro naus, sem sobreviventes, entre os quais estava Bartolomeu Dias" (Bechara e Spina, 1973: 206). Vemos a presença de um naufrágio no canto épico de Camões, tornando-os um elemento importante neste tipo de literatura.

Interessante que o Cabo das Tormentas foi nomeado pelo experiente navegador Bartolomeu Dias (1450 - 1500), no ano de 1488, após passar por fortes ventos e tempestades na região. Porém, foi renomeado pelo rei D. João II (1455 - 1495) de Cabo da Boa Esperança com obje- 
tivo de incentivar os navegadores que passavam por ali a caminho da Índia. Uma simples mudança de nome altera o modo como as navegações poderiam atravessá-lo: com medo de naufragarem ou com a esperança de chegarem à salvo ao seu destino.

A própria contradição do Império Português e seu projeto expansionista fica explícita nos relatos compilados por Gomes de Brito: a ciência que busca a expansão e o progresso mas que traz o desastre. A ânsia pelo comércio freada por obstáculos naturais (corais) que obrigaos a buscar a própria sobrevivência ao lucro. Os relatos não servem apenas como fonte histórico-literária mas para nos mostrar um outro lado, esquecido, da expansão marítima portuguesa.

\section{Fonte}

BRITO, Bernardo Gomes de. História trágico-marítima. Rio de Janeiro: Lacerda Editores: Contraponto Editora, 1998 [1735], p.95-120.

\section{Referências}

BECHARA, Evanildo; SPINA, Segismundo. Os Lusíadas: antologia. Rio de Janeiro: Grifo, 1973, p.206.

CAMÕES, Luís de. Os Lusíadas. São Paulo: Editora Lep, 1962 [1556], p.147-148.

CARVALHO, Joaquim Barradas de. O Renascimento português (em busca de sua especificidade). Lisboa: Imprensa Nacional, Casa da Moeda, 1980, p.07-40.

DORÉ, Andréa. Sitiados: O cerco às fortalezas portuguesas na Índia (1498 - 1622). São Paulo: Alameda, 2010, p.211-282.

LIMA, Francisco Ferreira de. Os padecimentos do Império: Gabriel 
Soares de Sousa e sua pequena Trágico-Marítima. Scripta, Belo Horizonte, v. 10, n. 19, p.180-188, $2^{\circ}$ sem. 2006.

MADEIRA, Maria Angélica. Notícia sobre a História Trágico-Marítima. Disponível em: <http://www.bocc.ubi.pt/pag/madeira-angelica-historiatragico-maritima.pdf $>$, acesso em março de 2014.

ROSSI, Paolo. Naufrágios sem espectador: a idéia de progresso. Trad. Álvaro Lorencini. São Paulo: Editora UNESP, 2000, p.23-47.

SEED, Patricia. Cerimônias de posse na conquista eurpéia do novo mundo (1492 - 1620). Trad. Lenita R. Esteves. São Paulo: Editora UNESP, 1999, p.143-186. 